\title{
Systems Engineering Technical Authority: A Path to Mission Success
}

\author{
James F. Andary \\ NASA/Goddard Space Flight Center \\ Greenbelt MD 20771 USA \\ 301-286-0612 \\ James.F.Andary@nasa.gov
}

\author{
Maria M. So \\ NASA/Goddard Space Flight Center \\ Greenbelt MD 20771 USA \\ 301-286-7411 \\ Maria.M.So@nasa.gov
}

\author{
Barry Breindel \\ BCB Associates LLC \\ 1922 Duffield Lane \\ Alexandria VA 22307 USA \\ 703-329-0635 \\ bcbllc@verizon.net
}

Copyright $\odot 2008$ by Andary, So and Breindel. Published and used by INCOSE with permission

\begin{abstract}
The systems engineering of space missions to study planet Earth has been an important focus of the National Aeronautics and Space Administration (NASA) since its inception. But all space missions are becoming increasingly complex and this fact, reinforced by some major mishaps, has caused NASA to reevaluate their approach to achieving safety and mission success.
\end{abstract}

A new approach ensures that there are adequate checks and balances in place to maximize the probability of safety and mission success. To this end the agency created the concept of Technical Authority which identifies a key individual accountable and responsible for the technical integrity of a flight mission as well as a project-independent reporting path. At the Goddard Space Flight Center (GSFC) this responsibility ultimately begins with the Mission Systems Engineer (MSE) for each satellite mission.

This paper discusses the Technical Authority process and then describes some unique steps that are being taken at the GSFC to support these MSEs in meeting their responsibilities.

Introduction. NASA programs and projects have directly contributed to characterizing and analyzing the Earth's land-masses, oceans and atmosphere from the planet's surface to space since the formation of the agency in 1958. One significant example of this is the Landsat program which consists of a series of Earth-observing satellite missions jointly managed by NASA and the U.S. Geological Survey. Since 1972, Landsat satellites have collected information about Earth from space. The science of remote sensing has matured with the multispectral images of 
the Landsat program. Landsat satellites have provided global coverage of Earth's continents and surrounding coastal regions for over three decades, enabling scientists to study the many aspects of our planet and to evaluate the dynamic changes caused by both natural and human processes.

Missions since Landsat have become even more complex. Hardware and software are integrated into platforms with autonomous capabilities that were only dreamed of a decade ago. The challenge of engineering these systems to meet cost, schedule and performance requirements within acceptable levels of risk has become more difficult. In recent years this has resulted in an engineering excellence initiative within the agency, one of the outcomes of which has been a revitalization of systems engineering.

\section{Technical Authority}

As part of the effort to achieve engineering excellence, the agency took steps to ensure that there are adequate checks and balances in place to maximize the probability of safety and mission success. To this end the agency created the concept of Technical Authority which identifies a key individual accountable and responsible for the technical integrity of a flight mission. A fundamental part of the Technical Authority concept is that it has provided for an engineering reporting path up through the organization which is independent of the project.

Previously when the systems engineering team identified a serious technical risk they had to work with the project manager to eliminate or mitigate that risk. Often the project manager, under cost and schedule pressures, would not approve the recommended technical solution, choosing instead to either accept the risk or implement only part of the recommended solution. The technical team had nowhere to appeal the decision. The project manager's decision was final.

At the same time there already existed an independent reporting path for the project system assurance managers (SAMs) up through the Office of System Safety and Mission Assurance. If the SAM discovered something that was not safe he/she did not have to go through the project manager. The SAM could go around the project directly up through his or her organization and ultimately to the agency administrator, if necessary.

This was considered to be a good model for the technical team as well. So in February 2006 the agency took a major step and issued an interim policy establishing the organizational independence of technical authority from programs and projects. As a result the lines of technical authority were now independent from, yet equal to, the programmatic lines of authority. The policy was later codified with the release of an updated NASA Program and Project Management Processes and Requirements Policy document (NASA 2007a).

Each of the ten NASA field centers is developing a Technical Excellence Implementation Plan describing the Center's implementation of the Technical 
Authority. Under this plan each Center Director will select a systems technical authority for each program and project at the Center. For example, this would be a chief engineer, systems engineer, or lead engineer who will exercise technical authority for that program or project. In addition, the plan specifies that the systems technical authority will reside in an engineering organization and be matrixed to support the program or project, coordinating all the engineering activities including discipline engineers.

Furthermore, the Center Director, or his/her designee, will appoint appropriate lead discipline engineers to serve as the technical authority for that discipline and all the engineers for that discipline will report to that individual. In other words, there will be a lead thermal engineer, for example, that will be the technical authority for the thermal engineering on the project and all the thermal engineers on the project will report to him or her.

All program and project managers are responsible for implementing the technical authority requirements on their program or project.

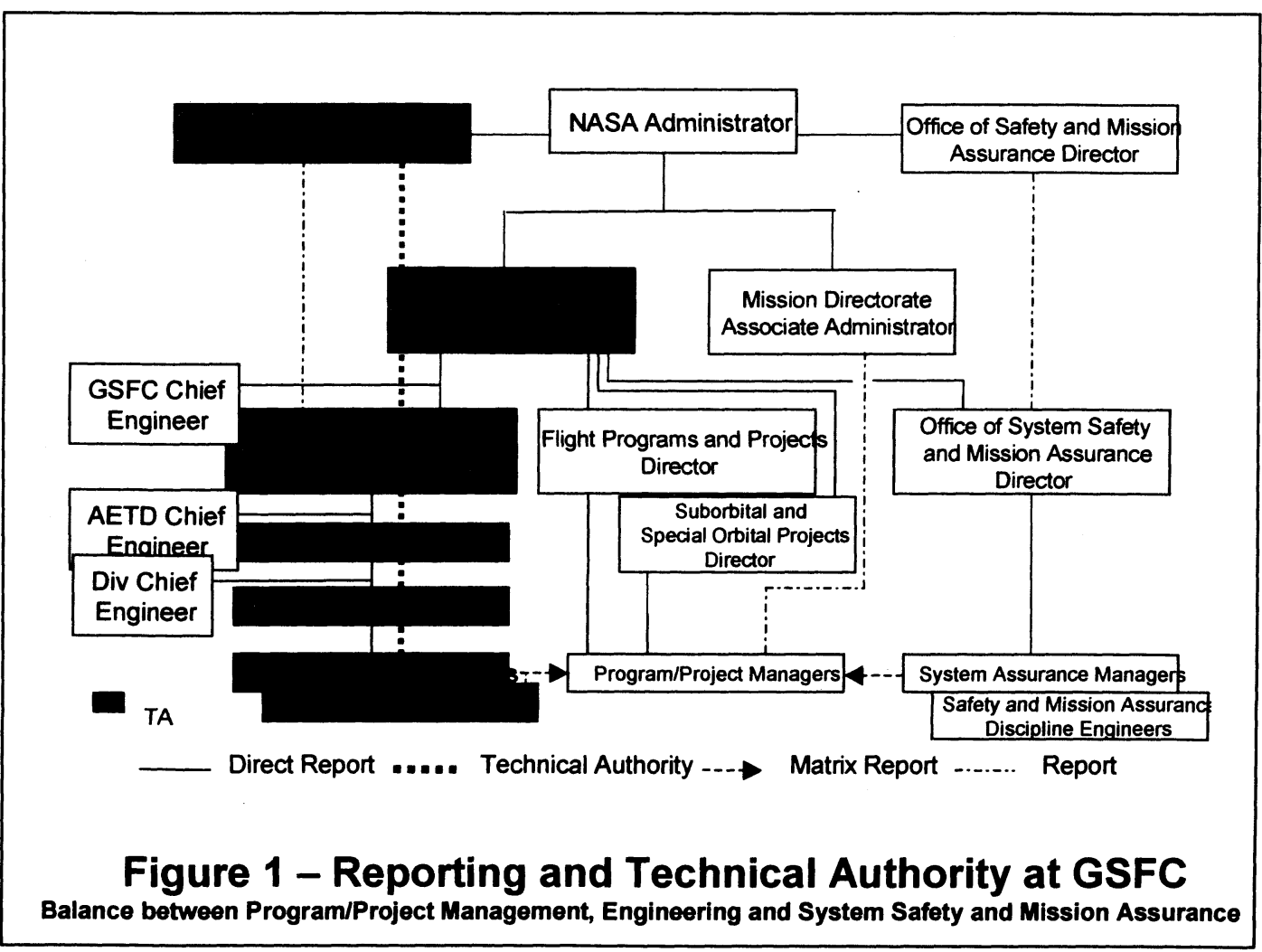

Figure 1 illustrates the implementation of the independent Technical Authority path at the Goddard Space Flight Center shown in green (NASA 2006). Note that there are actually three paths to the NASA Administrator shown in this diagram:

(1) Engineering (Technical Authority)

(2) Program and Project Management

(3) Safety and Mission Assurance 
It is the flow paths for technical and programmatic authority that are of interest here. The reporting path for Safety and Mission Assurance has been in place for many years and has been successfully resolving issues involving mission safety, quality and reliability. However, many technical issues fall strictly within the purview of systems engineering and are beyond the domain of Safety and Mission Assurance.

The other two flow paths for technical and programmatic authority illustrated in Figure 1 are clearly separate. The programmatic authority flows from the Mission Directorate at NASA Headquarters to the program and project managers assigned to the Center. The Technical Authority, on the other hand, flows from the NASA Chief Engineer to the Center Director. From there it flows down to the Director of Engineering, the Division Chiefs, and ultimately to the lead systems engineer on the program or project. Only those individuals in positions with formally delegated Technical Authority can exercise Technical Authority.

Although the project manager and the lead systems engineer have separate reporting paths for dissenting opinions, they must work together as a team to achieve technical excellence and mission success. Each must understand the other's position while recognizing the other's right to appeal. They must work together to try and resolve issues before they are reported up to higher authority.

If the lead systems engineer must appeal a decision of the project manager he must do it in a way which is viewed as maintaining the technical integrity of the project rather than a personal confrontation. The process of handling dissenting opinions is based on personal responsibility to adhere to the agency's shared core values of safety, teamwork, integrity, and mission success.

Clearly, the responsibility for technical authority ultimately falls on the shoulders of the lead systems engineer since he/she is closest to the day-to-day engineering effort. It is the goal of the Mission Systems Engineering Branch to assist these lead systems engineers in the execution of their responsibilities. There are 26 programs and projects at the Goddard Space Flight Center to which technical authority has been delegated. This gives a feel for the efficiency of scale that can be achieved with any assistance that can be given to the lead systems engineers or Mission Systems Engineers (MSE).

Flow of Technical Requirements. Along with the downward flow of technical authority there is a similar downward flow of technical requirements as illustrated in Figure 2. There are several sources of requirements: there are those that originate with the Office of the Administrator and the Office of Chief Engineer at NASA Headquarters and flow down to the Center Director (CD) [bold solid line]; there are institutional requirements that originate with the Center Director and flow down through engineering to the Lead System Engineer (LSE) and the Lead Discipline Engineers (LDE) supporting the programs and projects [bold dashed line]; and, finally, there are derived requirements that are generated within the project itself as a joint effort between the project manager and the lead systems engineer [narrow solid line]. 
Technical issues can arise from any of these requirements. It is the responsibility of the lead system engineer or MSE to be aware of all the requirements that affect his/her program or project and to ensure that each requirement is satisfied and verified. If a particular requirement does not pertain to his/her particular project then it is the responsibility of the MSE to obtain a waiver from the appropriate level of authority from which the requirement was issued.

Just becoming familiar with the sheer number of requirements contained in all the requirement documents is a tremendous burden to the MSEs. On top of that is the question of which requirements apply to which phase of the lifecycle. Some requirements apply to the early project formulation phases and others apply to the implementation phases. The requirements traceability tool presented later in this paper is an attempt to assist the MSE in satisfying all the requirements according to their lifecycle phase..

But first, it will be helpful to study an actual example where technical authority was exercised in order understand the difficult position that the MSEs are in and why they must exercise true systems thinking and be aware of all the requirements which affect their projects. We will next examine what was done to understand the enablers and barriers to systems thinking - a critical first step in assisting the MSEs in executing their responsibilities. And finally we will discuss the development of the requirements traceability tool.

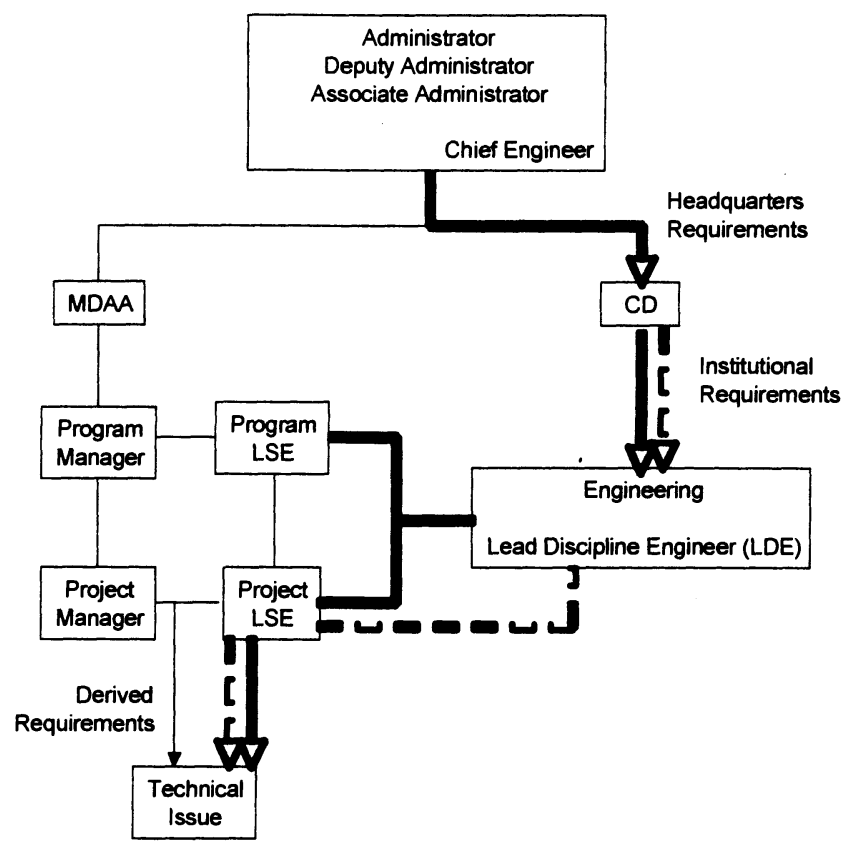

Figure 2 - Flow of Technical Requirements and Associated Challenges 


\section{Exercising Technical Authority}

To understand the heavy responsibility and pressures on someone serving as Technical Authority we consider an actual flight mission example ${ }^{1}$ that exhibits the enablers and barriers encountered in the role of the Technical Authority.

The situation is a weather satellite on the launch pad at Cape Kennedy. This satellite is a national asset critical to early detection and tracking of major storms. Failure of such an asset could possibly result in the loss of hundreds of lives and billions of dollars in property.

The Director of Engineering at Goddard Space Flight Center contacts the Mission Systems Engineer who is the Technical Authority on the project and asks him if the mission is ready for launch and if everyone is in agreement with the launch decision. These questions arise from the Agency Governance Model which enables the Technical Authority to exercise an appeals process to upper management outside the program/project chain of authority. In addition, the Governance Model reduces barriers that tended to isolate engineers from voicing concerns relative to program decisions based upon technical content.

For the case at hand, we will focus on one issue that has arisen that the Technical Authority must resolve prior to announcing to the Director of Engineering that the mission is a go. One of the launch vehicle components is a Composite Overwrapped Pressure Vessel (COPV). The COPV is qualified for a design life of 30 cycles to 5000 psi. The inner metallic liner of the vessel is prone to buckling however and requires regular, routine, inspection to confirm acceptability for flight. Following a nondestructive examination (NDE), a test article was cycled 7 times to 5000 psi without evidence of buckling. By NASA Goddard standards, this means that the tank life is based upon 7 cycles. In addition, the requirement on the factor of safety for cycle life is 4 , so that the tank has a cycle life of $7 / 4$ or 1.75 cycles. The project engineers take the conservative position that the actual cycle life is 1 , since allowable cycle life is an integer and the 1.75 figure should be rounded down to 1 , not rounded up to 2 . Basically, if factors of safety are not respected, why have them? Exercising the prerogative of the propulsion branch, which is the technical discipline organization responsible for pressure vessels such as this, the Technical Authority is informed that there is only one opportunity to launch the satellite.

The Technical Authority (TA) now has a written statement from engineering stating that there is a single launch opportunity for this mission. Knowing that the TA must answer to the Director of Engineering with regard to launch readiness as well as any dissenting opinions, we will review the surrounding circumstances and many inputs that the TA must consider in this decision.

First, the TA knows, from discussions with the project office and engineering that the COPV is pressurized 20 minutes before launch, or time of launch minus 20 minutes

\footnotetext{
${ }^{1}$ This example is attributed to a Mission Systems Engineer and Technical Authority.
} 
(T-20 minutes). If the mission is aborted within the 20 minutes of launch, and the allowable number of cycles is 1 , the tank must be left pressurized until the next launch attempt. This situation can easily arise at Cape Kennedy, for example, as a result of a sudden, fast-moving, thunderstorm. Since the tank has not been qualified for a long hold time, this is not acceptable. If the tank is depressurized until the next launch opportunity, the tank will be into its second cycle.

The TA is also aware, from discussions with the project office, that there is a 3-day launch window and that the cost of delay is $\$ 200 \mathrm{~K}$ per day. If the 3-day launch window is missed, the next launch cannot be attempted for 45 days due to other missions in the launch queue. The potential cost of delay is now $\$ 9 M$.

The TA is under pressure for a launch go-ahead from the project office. Also, the project office wants to have two launch opportunities during the 3-day launch window. At the same time, the Program Office, although believing that there is small inherent risk to the launch, does not want to establish an a priori waiver that will establish a precedent for other, future, programs. It is considering a recommendation to abort the launch and then process a waiver to allow the launch so that this becomes a onetime exception, not a precedent. Engineering is taking the position that 1.75 cycles should be treated as one cycle, not two. A contractor expert supporting the project sees a small inherent risk but says that the mission should be given the broadest possible window and a launch go-ahead should be authorized. The contractor provides his own safety analysis but basically says that he will do whatever the government directs. Finally, the TA gets another call from the Director of Engineering with the question: "What is your recommendation if we scrub the launch today (assuming the T-20 minute window is passed and the system is pressurized) should we attempt to launch tomorrow?"

With the information at hand, the TA decided in favor of recommending a mission launch. No one disagreed that the system could certainly withstand one launch cycle. Only if the launch were aborted would the number of system cycles become an issue. In this case, the launch was authorized and, as it turned out, was successful. In discussions with the TA, it was clear that a second launch would have been recommended during the 3-day launch window if it were necessary. The Missed Opportunity of missing the launch window, in terms of satellite unavailability and cost impact, overcame the "small inherent risk" to launch.

Although this example had a successful conclusion, it illustrates the difficulties facing the TA in making a decision, and that decision would not have been as easy if the satellite did not launch on the first attempt. Facing the issues of uncertainty, conflict, ambiguity, stress and high stakes consequences, the TA must exercise system thinking. System thinking allows the TA to see beyond the dissenting opinions of the discipline engineering organization, which was following the strict letter of the requirement. They insisted on a safety factor of 4 , and rightly so, since they are bound by the requirements imposed on their discipline. But system thinking takes in the big picture and considers all aspects and consequences of the situation and 
weighs the requirement against the risk: what is the probability of occurrence and what are the consequences? But how does one develop system thinking? What are the enablers and barriers to system thinking within an organization? The Mission Systems Engineering Branch attempted to answer these questions.

\section{Development of Critical System Thinking: Enablers and Barriers}

As described in the previous sections, the mission systems engineers are responsible for increasingly complex missions. In order to better understand of how to develop qualified senior systems engineers to satisfy NASA satellite mission needs, the Mission Systems Engineering Branch at the Goddard Space Flight Center collaborated with industry and academia regarding the practices and methods by which senior systems engineers are best prepared for their roles. In December 2006, the branch established an agreement with Professor Donna Rhodes from the MIT Lean Advancement Initiative (LAl) (formerly known as the Lean Aerospace Initiative) to perform surveys on the enablers and barriers in the development of systems thinking in engineers at Goddard. This effort was to extend Dr. Heidi Davidz's doctoral dissertation on the same subject (Davidz 2005). In January 2007 a Masters Degree candidate at MIT performed a one-month study at Goddard using interviews and surveys based on Dr. Davidz's technique. This technique involved a carefully constructed question set that had been used to investigate system thinking at ten aerospace companies. The results of this technique applied to our branch provided us a unique opportunity to reflect on our practices of systems engineer development (Adams 2007).

As shown in numerous research findings, system thinking is one of the key attributes of a successful systems engineer. Our MIT study goal was first to understand how our senior systems engineers with proven track records actually developed their system thinking. The second goal was to understand and eliminate the obstacles that prevent our engineers from developing such thinking. One of the key questions used in the interviews was, "What enablers or barriers have you seen to the development of systems thinking in engineers?"

In terms of barriers, 42 percent of those surveyed said that being too detail-oriented could be a barrier. 12 percent indicated that lack of interest on the part of engineers to become systems engineers was a barrier and 3 percent indicated that limited exposure to systems engineering was a barrier. Meanwhile five engineers said that organizational culture was an important factor and could be a barrier. From the responses of the interviews, it seems that the barriers to the development of systems thinking within our organization are largely intangible.

In terms of enablers, 30 percent of those surveyed said that exposure to how subsystems interact was a key enabler. 27 percent indicated that systems engineering training programs such as our internal Systems Engineering Education and Development (SEED) program are enablers. Another 21 percent indicated that 
mentoring programs were strong enablers. Our interview results align well with the results obtained from interviews at the aerospace companies described in $\mathrm{Dr}$. Davidz's original work, particularly in the areas of experience, exposure to how things interact and training.

During the interviews, our engineers indicated a number of personal characteristics that seem to favor the development of system thinking in an individual. Such characteristics as curiosity, big picture thinking, good personal interaction with people, open mindedness, good communication, and understanding (or wanting to understand) how systems interact are the individual characteristics that seem to predict the development of systems thinking.

Based on the interview results, our immediate focus was to increase our engineers' exposure to a variety of mission activities. For example, we have worked diligently to ensure that each of our systems engineers serves on a peer review panel for a mission in addition to the mission that he/she is working on. That allows them the opportunity to see how other projects deal with problems and what unique processes work for them. We also established small mission focus groups so that the engineers can share their knowledge and experience among themselves. And finally, we organized systems engineering seminars once a month to expose the engineers to a broad range of systems engineering experiences both inside and outside of the agency. Although this is just a start, they are important steps in broadening the system thinking view of the systems engineers who serve as Technical Authority.

\section{Systems Engineering Requirements Traceability}

Earlier we addressed the new Technical Authority model invoked at NASA and the complexities associated with its application. The impact of the new TA can be visualized if one considers that there are 64 Mission System Engineers (MSEs) at Goddard of which 18 have Technical Authority responsibilities in their specialties. These MSEs provide support for over 20 space mission projects at any given time. The MSE function supports the Program/Project Managers and assures the program office that all Systems Engineering requirements are satisfied at the Program/Project Milestone Reviews. As a result the Mission Systems Engineering Branch at Goddard has undertaken the task of seeking ways to ease the burden of day-to-day pressures placed on the MSE wherever possible so that the MSE can focus attention on broader systems engineering issues, including TA responsibilities.

The flow of requirements imposed upon the MSE is depicted in Figure 3. This depicts how the generic flow of Figure 2 is specifically applied to the systems engineering effort at Goddard. The parent document for Systems Engineering is the agency Systems Engineering Processes and Requirements NPR 7123.1A (NASA 2007b). In turn, the requirements of the NPR are implemented by the individual NASA Centers which in the case of Goddard results in the Goddard Procedural Requirements for Systems Engineering GPR 7120.5A. In addition to the GPR 7120.5A, requirements are imposed upon the MSE from other documents described in Figure 3 covering 
areas such as risk management, engineering peer reviews, Rules for the Design, Development, Verification and Operation of Flight Systems (known as the "GOLD Rules") and Integrated Independent Review Guidance. In general, requirements contained in the referenced documents have shortcomings with regard to their application by the MSE. The stated requirements typically are not directly tied to the project life cycle phases, the activities that are conducted to meet the requirements are not delineated and the requirements that are the responsibility of the MSE are not identified as such. In order to correct these limitations the GSFC Mission Systems Engineering Branch has undertaken the development of a System Engineering Requirements Traceability (SERT) tool to aid the MSE.

The objectives for the SERT tool were derived from several senior systems engineers within the branch:

(1) Provide a mechanism to link the agency NPR 7123 requirements to the Goddard Systems Engineering GPR 7120.5A as part of the implementation of the NPR as mandated by the NASA Office of the Chief Engineer.

(2) Develop a process to generate, distribute, and update traceability of systems engineering compliance matrices from NASA Procedural Requirements to Goddard Procedural Requirements to flight project requirements.

(3) Satisfy GSFC requirements management principles, namely, " $A$ requirements management process shall be developed throughout the lifecycle that includes requirements identification, tracking, and documentation as well as a flow-down and traceability of Level 1 requirements to implementation requirements." (GSFC 2006)

(4) Provide a tool to assist lead systems engineers, as the Technical

Authority, in readily identifying and complying with all NASA and GSFC requirements.

(5) Locate all MSE requirements in one place with references to their source.

(6) Make requirements traceable from the agency NPR 7123.1, the GSFC GPR 7120.5A and other relevant Goddard Procedures and Requirements.

(7) Categorize requirements and the activities associated with the requirements by mission lifecycle phase.

(8) Design the SERT tool with an open architecture that will permit ease of expansion to incorporate future additions of Goddard MSE requirements documents and new or revised agency NPRs. The SERT tool should be able to accommodate added capabilities such as links to templates for such things as the Systems Engineering Management Plan (SEMP). 


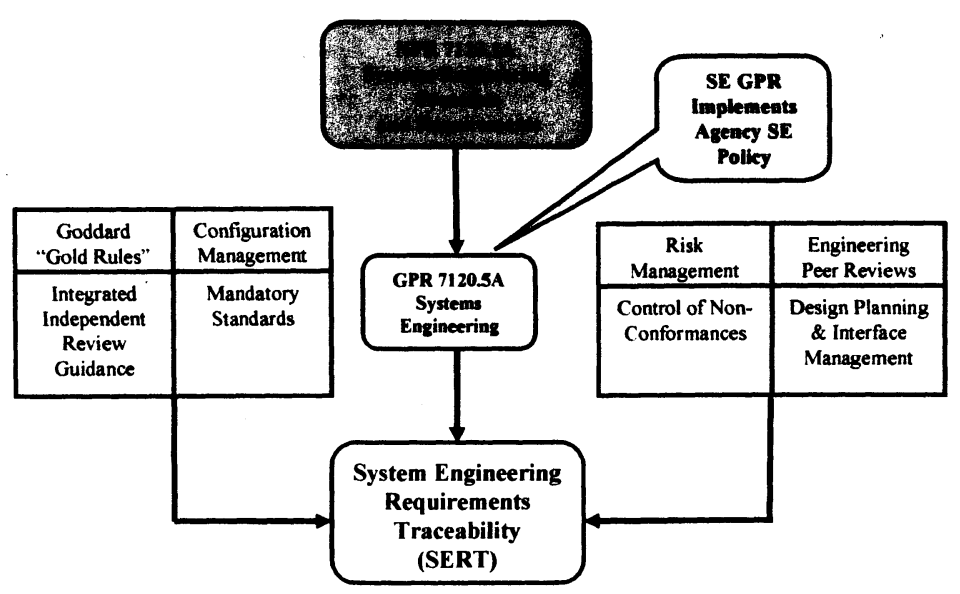

Figure 3 - Requirements Flow to SERT Tool

The SERT tool is first intended to provide value added to the Mission Systems Engineer by reducing the time expended by the MSE in identifying the complete set of systems engineering requirements for a project. Secondly, the tool reduces the frequency of errors of omission due to missed requirements. Thirdly, having a handle on all the requirements will enable the MSE to provide better support for the project major milestone reviews and the systems engineering peer reviews and will permit early identification and resolution of requirement issues. Fourthly, the Technical Authority can get an early look at which requirements drive the design and also which requirements are not applicable and may need a waiver. Finally, the SERT tool provides for traceability of requirements among documents and between agency and the Center procedures and requirements which aids the verification and validation process.

The SERT tool uses the CORE ${ }^{\circledR}$ software tool ${ }^{2}$ to provide requirements traceability and to satisfy the above requirements. Using CORE ${ }^{\circledR}$ and navigating the SERT database, the MSE is able to extract information by sorting data as follows:

a. Requirements by project life cycle phase

b. Activities by project life cycle phase

c. Requirements by document

d. Complete documents (from the "Reference Library")

The NASA project lifecycle appears as Figure 4. GSFC has incorporated a systems

${ }^{2}$ CORE is a registered trademark of Vitech Corporation 
engineering peer review process into the project life cycle and these reviews are shown in the figure as red diamonds at locations preceding the major project reviews.

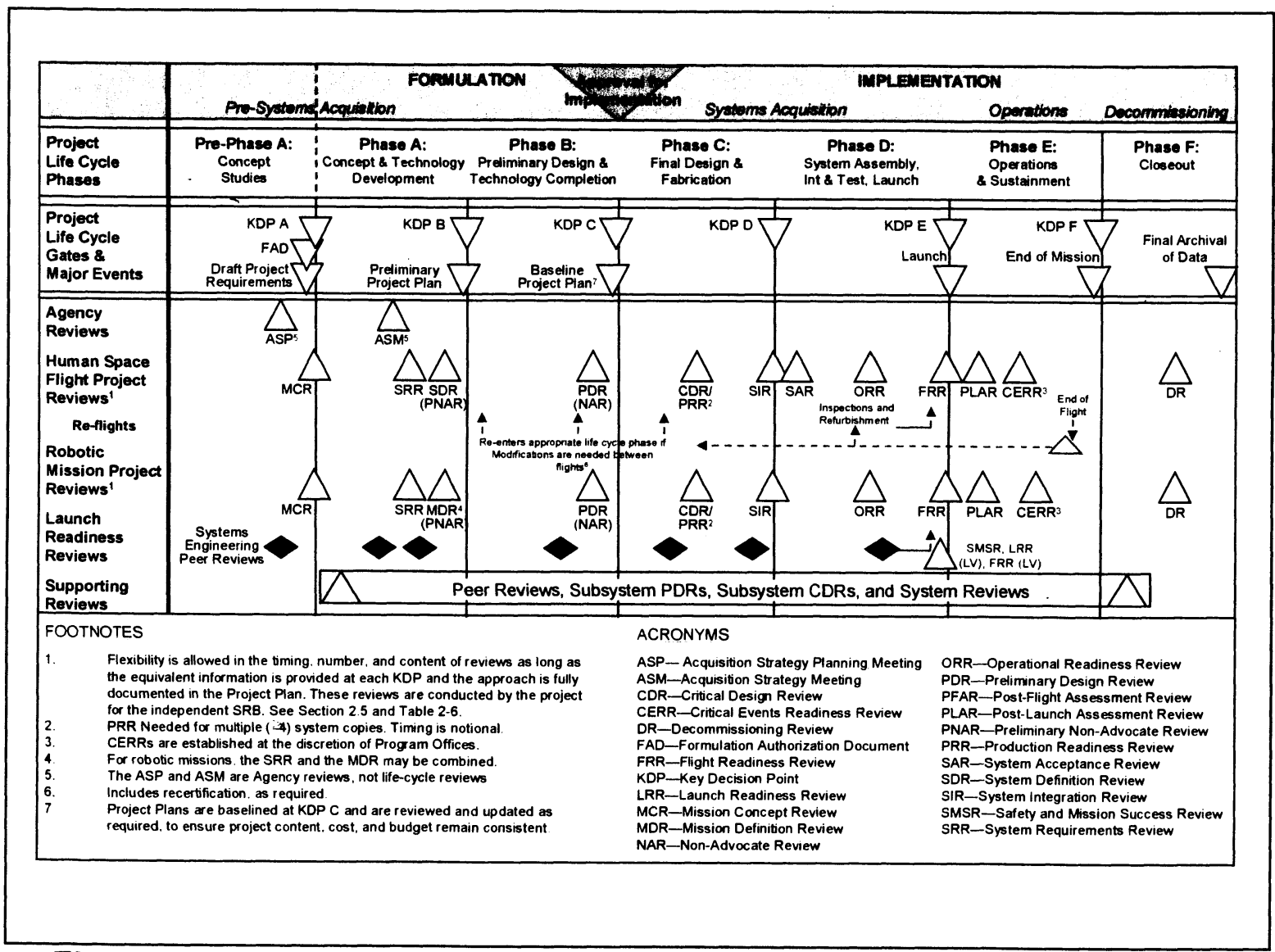

Figure 4 - The NASA Project Life Cycle (Showing the SE Peer Reviews) 


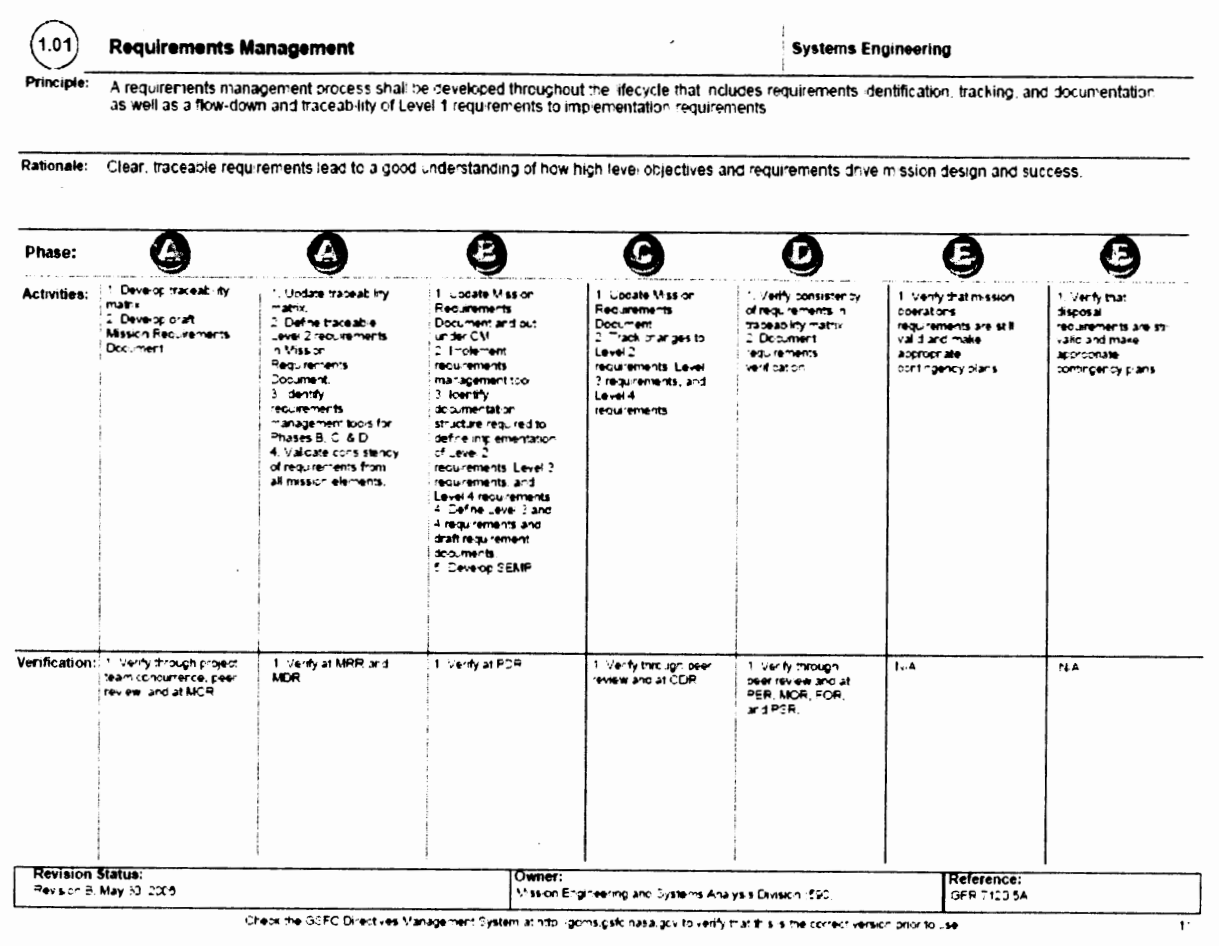

Figure 5 - GOLD Rules Activities Example

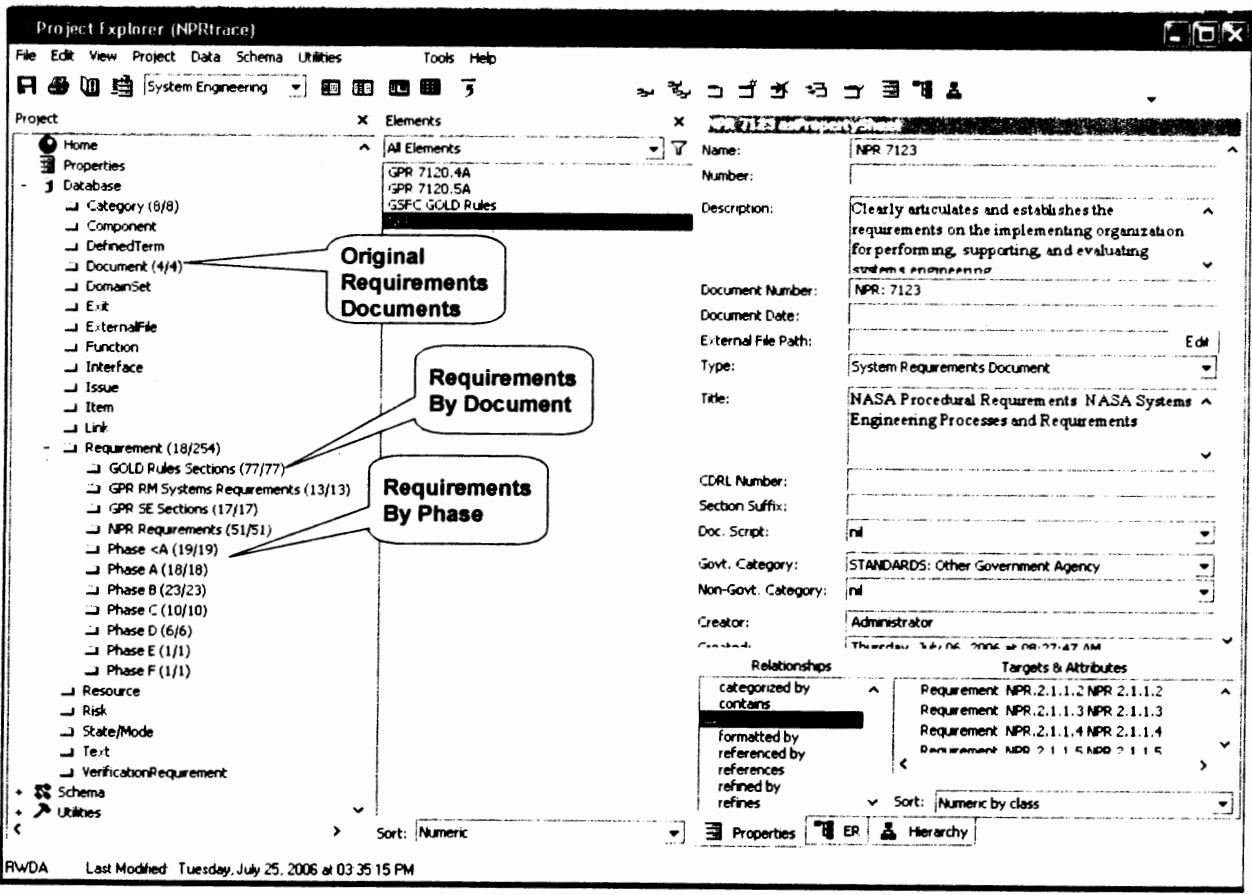

Figure 6 - CORE User Interface for SERT

Prior to loading the SERT database it is necessary to review the documents listed in Figure 3 and identify the requirement statements, corresponding project life cycle 
phase and determine if the requirement is applicable to the MSE function.

The final important input to the SERT database is the distribution of activities which are performed by the MSE according to life cycle phase for a particular GPR or Standard. Figure 5 provides an example of this input for the GSFC "GOLD Rules" Standard.

With all inputs identified as shown in the above figures and tables, the MSE requirements data is loaded into the SERT tool using the CORE ${ }^{\circledR}$ software. Figure 6 shows the CORE user interface for the SERT. As developed, the SERT tool can be navigated to satisfy the objective of providing the MSE immediate access to all requirements and activities imposed by the governing Center documents across the lifecycle phases of a GSFC project.

\section{Summary}

Faced with the new role as Technical Authority for a program or project, the Mission Systems Engineer has taken on serious responsibilities that demand a solid foundation in system thinking and a firm grasp of all the requirements levied on his mission. The home organization, the Mission Systems Engineering Branch, has taken steps to first understand the enablers and barriers to system thinking and then to provide assistance to the MSEs in developing system thinking. In addition the branch has developed a tool to assist the MSE in navigating and tracing all the applicable requirements both by document and by lifecycle phase.

\section{References}

Adams, Danielle, "Enablers and Barriers to Systems Thinking: Results from a Study at GSFC", June 2007

Davidz, Heidi, "Enabling Systems Thinking to Accelerate the Development of Senior Systems Engineers", Doctoral Dissertation, MIT, 2005

GSFC Rules for the Design, Development, Verification and Operation of Flight Systems, GSFC-STD-1000, Rev. C.2, December 2006

NASA GSFC Technical Authority Implementation Plan, NASA Goddard Space Flight Center, May 2006

NASA Space Flight Program and Project Management Requirements, NASA Procedural Requirements, NPR 7120.5D, 2007

NASA Systems Engineering Processes and Requirements, NASA Procedural Requirements, NPR 7123.1A, 2007 


\section{Biographies}

Mr. Andary is a senior systems engineer at NASA's Goddard Space Flight Center. He graduated with a BS Degree in Mathematics from Boston College and obtained his MA Degree in Mathematics from the University of Maryland. He joined the Guidance and Control Branch in 1969 and served in the Engineering Directorate until 1986 at which time he transferred to the Flight Projects Directorate where he served as systems engineer on a number of flight projects. He is an associate fellow of AIAA and a member of American Astronautical Society and INCOSE. He is an emeritus member of the AIAA Space Systems Technical Committee, the INCOSE Space Systems Working Group and represents GSFC on NASA's Systems Engineering Working Group.

Ms. So is an Associate Chief for the Mission Engineering and System Analysis Division at NASA's Goddard Space Flight Center. She graduated with her MA degree in Computer Science from University of Calgary, Canada and her BA degree from University of California, Berkeley. She joined the Hubble Space Telescope Project as the Operations Data Manager in 1992. She was the Ground System Manager for the Second Servicing Mission. She recently served as the Branch Head of the Mission Systems Engineering Branch. She was the NASA Technology Inventory Manager and captured its annual \$1.3B technology investments for all ten NASA Centers. She is a member of the AIAA Space Systems Technical Committee, the INCOSE Systems Requirement Working Group, and IEEE.

Mr. Breindel is currently a support contractor with the NASA Goddard Space Flight Center (GSFC) Mission Systems Engineering (MSE) Branch and the NASA Office of the Chief Engineer. He has Masters Degrees from the Massachusetts Institute of Technology (Nuclear Engineering) and Georgetown University (National Security Studies). In addition, Mr. Breindel has a Business Administration Degree from the University of San Francisco and a Bachelor of Science Degree from New York University (Engineering Science). Over the past four years he has been involved with the development of new systems engineering processes and guidelines at NASA. In particular, Mr. Breindel has been directly involved in planning and executing the development of a Systems Engineering Requirements Traceability Website for the GSFC MSE Branch. His NASA activities follow a long career in the aerospace/defense industry which started with the development of space nuclear power systems utilizing liquid metal cooled reactors, energy conversion technology and the Nuclear Engine for Rocket Vehicle Application (NERVA). 